\title{
Trends and inter-annual variability of methane emissions derived from 1979-1993 global CTM simulations
}

\author{
F. Dentener ${ }^{1}$, M. van Weele ${ }^{2}$, M. Krol ${ }^{3}$, S. Houweling ${ }^{4}$, and P. van Velthoven ${ }^{2}$ \\ ${ }^{1}$ JRC, Institute for Environment and Sustainability, I-21020 Ispra (Va), Italy \\ ${ }^{2}$ KNMI, de Bilt, the Netherlands \\ ${ }^{3}$ IMAU, Utrecht University, the Netherlands \\ ${ }^{4}$ MPI Biogeochemistry, Jena, Germany
}

Received: 6 February 2002 - Published in Atmos. Chem. Phys. Discuss.: 7 March 2002

Revised: 30 September 2002 - Accepted: 11 January 2003 - Published: 3 February 2003

\begin{abstract}
The trend and interannual variability of methane sources are derived from multi-annual simulations of tropospheric photochemistry using a 3-D global chemistrytransport model. Our semi-inverse analysis uses the fifteen years (1979-1993) re-analysis of ECMWF meteorological data and annually varying emissions including photochemistry, in conjunction with observed $\mathrm{CH}_{4}$ concentration distributions and trends derived from the NOAA-CMDL surface stations. Dividing the world in four zonal regions (45$90 \mathrm{~N}, 0-45 \mathrm{~N}, 0-45 \mathrm{~S}, 45-90 \mathrm{~S}$ ) we find good agreement in each region between (top-down) calculated emission trends from model simulations and (bottom-up) estimated anthropogenic emission trends based on the EDGAR global anthropogenic emission database, which amounts for the period 1979-1993 2.7 $\mathrm{Tg} \mathrm{CH}_{4} \mathrm{yr}^{-1}$. Also the top-down determined total global methane emission compares well with the total of the bottom-up estimates. We use the difference between the bottom-up and top-down determined emission trends to calculate residual emissions. These residual emissions represent the inter-annual variability of the methane emissions. Simulations have been performed in which the year-to-year meteorology, the emissions of ozone precursor gases, and the stratospheric ozone column distribution are either varied, or kept constant. In studies of methane trends it is most important to include the trends and variability of the oxidant fields. The analyses reveals that the variability of the emissions is of the order of $8 \mathrm{Tg} \mathrm{CH}_{4} \mathrm{yr}^{-1}$, and likely related to wetland emissions and/or biomass burning.
\end{abstract}

\section{Introduction}

Atmospheric methane $\left(\mathrm{CH}_{4}\right)$ concentrations have more than doubled since the pre-industrial era. This increase has resulted in a radiative forcing of about $0.5 \mathrm{Wm}^{-2}$. Methane is

Correspondence to: F. J. Dentener (frank.dentener@jrc.it) therefore the most important increasing greenhouse gas after $\mathrm{CO}_{2}$. During the past two decades (from 1978-1998) the globally averaged methane concentration has increased from about 1520 to 1745 ppbv (Prather et al., 2001). The rate of the methane increase has varied substantially during this period. Values were of the order of $20 \mathrm{ppbv} \mathrm{yr}^{-1}$ during the $1970 \mathrm{~s}$, a rather constant value of $12 \mathrm{ppbv} \mathrm{yr}^{-1}$ in the $1980 \mathrm{~s}$, and almost zero increase in the years 1992 and 1993 (Lelieveld et al., 1998; Dlugokencky et al., 1998). Over the period 1993 to 1998 the rate of increase was about $5 \mathrm{ppbv} \mathrm{yr}^{-1}$.

A remarkable depression of the methane growth rate occurred during 1992 and 1993, which may be attributed to the impact of the eruption of Mt. Pinatubo in June 1991. This eruption has likely caused lower northern latitude wetland emissions (Hogan and Harris, 1994) and changes in the tropospheric $\mathrm{OH}$ content related to stratospheric ozone depletion (e.g. Bekki et al., 1994). The Pinatubo eruption clearly showed that the observed methane growth rate and its variations are the result of an imbalance between methane emissions (sources) and destruction rates (sinks).

This work attempts to assess the trend and inter-annual variability of methane emissions over the period 1979-1993 by applying a a mass balance approach implemented in a CTM. As an a priori estimate the model uses the natural and anthropogenic $\mathrm{CH}_{4}$ emissions evaluated by Houweling et al. (1999), see Table 1. These emissions do not contain inter-annual variability. The effective $\mathrm{CH}_{4}$ emissions are calculated from simulations in which the $\mathrm{CH}_{4}$ observations from the NOAA CMDL network are assimilated into the model. We use the results of a set of simulations used previously to study the trends and variability of ozone $\left(\mathrm{O}_{3}\right)$ during the same time period (Lelieveld and Dentener, 2000). Here the simulations (including meteorological and photochemical variability) are used to investigate whether (top-down) model calculated $\mathrm{CH}_{4}$ emissions and derived trends are consistent with current (bottom-up) knowledge on the temporal and spatial changes in the anthropogenic and/or natural

(C) European Geosciences Union 2003 
Table 1. Emissions $\mathrm{Tg} \mathrm{CH}_{4} \mathrm{yr}^{-1}$ evaluated by Houweling et al. (1999) used as an a-priori estimate

\begin{tabular}{lrrrrr}
\hline region & 90N-45N & $45 \mathrm{~N}-0 \mathrm{~N}$ & 0S-45S & 45S-90S & Global \\
\hline coal mining & 13.5 & 22.1 & 2.4 & 0.0 & 38.0 \\
soil oxidation & -13.3 & -10.6 & -6.0 & -0.1 & -30.0 \\
wild animals & 1.4 & 1.9 & 1.7 & 0.0 & 5.0 \\
domestic ruminants & 21.4 & 51.9 & 19.1 & 0.6 & 93.0 \\
oceans & 5.0 & 4.9 & 3.9 & 1.2 & 15.0 \\
termites & 1.9 & 9.6 & 8.5 & 0.0 & 20.0 \\
fossil+domestic fuel & 2.3 & 14.9 & 2.9 & 0.0 & 20.0 \\
gas production & 24.3 & 24.7 & 2.0 & 0.1 & 51.0 \\
vulcanoes & 0.0 & 2.2 & 1.3 & 0.0 & 3.5 \\
biomass burning & 0.0 & 19.5 & 22.5 & 0.0 & 42.0 \\
permafrost & 1.0 & 0.0 & 0.0 & 0.0 & 1.0 \\
landfills & 11.5 & 31.6 & 4.8 & 0.0 & 48.0 \\
rice & 0.5 & 69.8 & 9.7 & 0.0 & 80.0 \\
wetlands & 31.4 & 48.4 & 65.1 & 0.0 & 145.0 \\
sum natural & 27.4 & 56.4 & 74.5 & 1.2 & 159.5 \\
sum anthropogenic & 73.4 & 234.5 & 63.4 & 0.7 & 372.0 \\
\hline
\end{tabular}

methane sources.

Bottom-up estimates of the global methane source strength over the past two decades amount to about 500-600 Tg $\mathrm{CH}_{4} \mathrm{yr}^{-1}$ (Prather et al., 2001). Extensive overviews on individual methane sources are presented in e.g. Lelieveld et al. (1998). Natural sources consist of high and low latitude wetlands, termites, wild animals, oceans, volcanoes and wildfires. Houweling et al. (2000) evaluated the (preindustrial) annual wetland emissions to be between 130 $194 \mathrm{Tg} \mathrm{CH}_{4} \mathrm{yr}^{-1}$, all other natural sources amounting to about $40-70 \mathrm{Tg}$. Anthropogenic sources are related to production and consumption of gas and oil, ruminants, landfills, rice agriculture and biomass burning. Most bottom-up estimates of the global anthropogenic sources are remarkably similar and amount to $315-350 \mathrm{Tg} \mathrm{CH}_{4} \mathrm{yr}^{-1}$ (Prather et al., 2001, and references therein).

The estimates of the latitudinal distributions of the emissions by various authors show substantially less consensus. For example, an early study by Fung et al. (1991) distributes the anthropogenic and natural emissions over the Northern and Southern Hemisphere (NH and $\mathrm{SH}$ ) by a ratio 499 to $144 \mathrm{Tg} \mathrm{CH} \mathrm{Cr}^{-1}$. Lelieveld et al. (1998) suggest a NH-SH ratio of 399 to $123 \mathrm{Tg} \mathrm{CH}_{4} \mathrm{yr}^{-1}$. The inverse model results of Hein et al. (1997) indicate a ratio of 416 to $162 \mathrm{Tg} \mathrm{CH}_{4} \mathrm{yr}^{-1}$, whereas the adjoint inverse model of Houweling et al. (1999) rather calculates 340 and $165 \mathrm{Tg} \mathrm{CH}_{4} \mathrm{yr}^{-1}$, for the $\mathrm{NH}$ and $\mathrm{SH}$, respectively. Therefore, there are large uncertainties associated with the individual sources of methane and their geographical and temporal distribution.

What do we know about emission trends? Recently, Dlugokencky etal. (1998) analysed the NOAA CMDL $\mathrm{CH}_{4}$ measurements for the period 1984-1996. They suggested that during this period $\mathrm{CH}_{4}$ emissions must have remained almost constant. However, this conclusion strongly depends on the assumption that the global hydroxyl $(\mathrm{OH})$ radical concentrations also remained constant. At present, this topic is strongly under debate. Prinn et al. (1995) and Prinn and Huang (2001) used methyl-chloroform (MCF) observations to derive an $\mathrm{OH}$ trend of $0.0 \% \pm 0.2 \% \mathrm{yr}^{-1}$ for the period 1978-1993. In contrast, using the same observational data-set, but a different statistical analysis technique and assumptions on initial pre-1978 conditions, Krol et al. (1998) and Krol et al. (2001) derive a positive $\mathrm{OH}$ trend of $0.46 \pm$ $0.6 \% \mathrm{yr}^{-1}$. The latter trend estimate is more consistent with the results of the simulations used in this study as well as an independent model study by Karlsdòttir et al. (2000). In a recent study Prinn et al. (2001) derive a strong positive $\mathrm{OH}$ trend for the period 1979-1989 followed by a negative trend in the period 1990-2000.

The global bottom-up estimate of $500-600 \mathrm{Tg} \mathrm{CH}_{4} \mathrm{yr}^{-1}$ is roughly consistent with top-down model estimates on the global methane source where global $\mathrm{OH}$ is calibrated using observed MCF concentrations (Houweling et al., 2000). However, these top-down estimates are also associated with large uncertainties of at least $10 \%$ (see Sect. 5). In addition, due to the scarcity of measurements it seems at present not possible to determine from the concentration measurement at the surface one unique source/sink configuration (Hein et al., 1997; Fung et al., 1991). In future the availability of isotopic data may help to improve the situation (e.g. Lassey et al., 1993). Also upcoming satellite data measuring tropospheric methane columns may improve our knowledge on the geographical and temporal variation of methane sources. This work does not aim to improve the knowledge on the $\mathrm{CH}_{4}$ source distributions and strengths, but rather focuses on emission variability and trends. 
The CTM used in this study is described in Sect. 2. Details on the methodology to derive the emission trends for the period 1979-1993 are given in Sect. 3. This period was chosen, since we have a consistent meteorological dataset from the ECMWF-ERA15 dataset, as well as an emission dataset for this period. In Sect. 4 we will present results for 3 different simulations with different combinations of varying meteorology, emissions and stratospheric ozone boundary conditions. The sensitivity of the method to possible measurement and model errors will be discussed in Sect. 5. Conclusions are presented in Sect. 6.

\section{Global chemistry transport model}

The global chemistry-transport model TM3 (Heimann, 1995; Houweling et al., 1998; Lelieveld and Dentener, 2000, and references therein) is used in this study at a spatial resolution of $10^{\circ}$ longitude and $7.5^{\circ}$ latitude with 19 vertical layers. Six-hourly meteorological fields from the ECMWF (European Centre for Medium Range Weather Forecast) ERA15 re-analysis for the years 1979-1993 (Gibson et al., 1997) are utilised. These fields include global distributions for horizontal wind, surface pressure, temperature, humidity, liquid water content, ice water content, cloud cover, large-scale and convective precipitation. Tracer advection is simulated with the so-called 'slopes' scheme (Russell and Lerner, 1981). Convective tracer transport is calculated with a mass flux scheme that accounts for shallow, mid-level and deep convection (Tiedke, 1989). Turbulent vertical transport is calculated by stability dependent vertical diffusion (Louis, 1979). A detailed comparison between simulated and measured $\mathrm{Rn}^{222}$ has indicated that the synoptic scale model transport properties are represented relatively accurately at the applied resolution (Dentener and Crutzen, 1994). Also the comparison between modelled ozone and several background ozone soundings as presented in Lelieveld and Dentener (2000), revealed a quite satisfactory agreement between model and measurements.

The chemical scheme is based on a modified version of $\mathrm{CBM} 4$ that describes the chemistry of $\mathrm{CH}_{4}-\mathrm{CO}-\mathrm{NMHC}-\mathrm{NO}_{\mathrm{x}}$ (Houweling et al., 1998) as well as $\mathrm{NH}_{\mathrm{x}}$, DMS, $\mathrm{SO}_{\mathrm{x}}$ (Dentener and Crutzen, 1994). In its present form the scheme accounts for 24 photo-dissociation and 67 thermal reactions as well as reactions on aerosols and in clouds. Dry deposition of gases and aerosols is parameterized according to Ganzeveld et al. (1998), and wet deposition according to Guelle etal. (1998). Photolysis frequencies are calculated with the scheme by Landgraf and Crutzen (1998), including the effects of clouds, surface albedo and the overhead ozone column following Krol and Van Weele (1997).

Stratospheric boundary conditions are applied to ozone, methane and nitric acid $\left(\mathrm{HNO}_{3}\right)$. At levels above $50 \mathrm{hPa}$ stratospheric ozone is relaxed towards the zonal and monthly mean ozone column measurements by the Total Ozone Map- ping Spectrometer (TOMS) (McPeters, 1996) using a vertical distribution from an ozone climatology representative for the 1980s (Fortuin and Kelder, 1998). The ozone column above $10 \mathrm{hPa}$ is prescribed. The 3-D ozone variability in the stratosphere is maintained by simulated transport. Since TOMS measurements are not available for a large part of the year 1993, we apply the 1992 TOMS measurements for 1993.

$\mathrm{CH}_{4}$ is destroyed mainly by $\mathrm{OH}$ in the troposphere and by reactions with $\mathrm{OH}, \mathrm{Cl}$ and $\mathrm{O}^{1} \mathrm{D}$ in the stratosphere. Since TM3 does not explicitly consider stratospheric reactions, we apply in the stratosphere a methane loss rate varying between 38 and $42 \mathrm{Tg} \mathrm{CH}_{4} \mathrm{yr}^{-1}$, based on 2-D model results of Brühl and Crutzen (1993).

Except for methane (see Sect. 3), yearly anthropogenic emissions of $\mathrm{NO}_{\mathrm{x}}, \mathrm{CO}, \mathrm{NMHC}, \mathrm{SO}_{\mathrm{x}}$, and $\mathrm{NH}_{3}$ are directly taken from the emission database developed by Aardenne etal. (2001). This database, which is based on the widely used EDGAR emission database (Olivier et al., 1999), describes the development of emissions during the period 1890-1990. We used the base years 1970, 1980, 1985, and 1990, and linearly interpolated the results for the years 1979 1990. Emissions for the period 1991-1993 are obtained by extrapolation of the 1990 emission using $\mathrm{CO}_{2}$ emission statistics obtained from Marland et al. (2000). Natural emissions of $\mathrm{O}_{3}$ precursor gases are prescribed as described in Houweling et al. (1998). The emission data-set does not account for their possible inter-annual variability, with the exception of $\mathrm{NO}_{\mathrm{x}}$ resulting from lightning discharges, which is coupled to modelled convection, and therefore lightning $\mathrm{NO}_{\mathrm{x}}$ emissions show an inter-annual variability of about $0.5 \mathrm{TgN} \mathrm{yr}^{-1}$.

\section{Analysis method}

We use a relatively simple mass-balance inversion method coupled to a rather complex model of atmospheric transport and chemistry to assess the consistency of the present-day information on methane emissions, atmospheric chemistry and observations. This approach has the advantage over more sophisticated inversion formalisms such as the Green's function approach or Kalman filtering, that it is easier to implement and computationally less expensive. A disadvantage, however, is a loss of accuracy resulting from a simplified treatment of source-inference rules. We demonstrate by a test with synthetic emissions (see Appendix), that these errors are expected to be small on the large temporal and spatial scales that we use in this study. Another advantage of our approach is that it advoids cumbersome iterative linearisations of this (weakly) non-linear inversion problem. Unlike previous studies, our method guarantees that feedbacks of $\mathrm{CH}_{4}$ on $\mathrm{OH}$ are accounted for in a consistent way. Therefore, the use of our simple method, provides an alternative for more conventional inversion methods, for which the real uncertainties are not very well known (compare e.g. Houwel- 

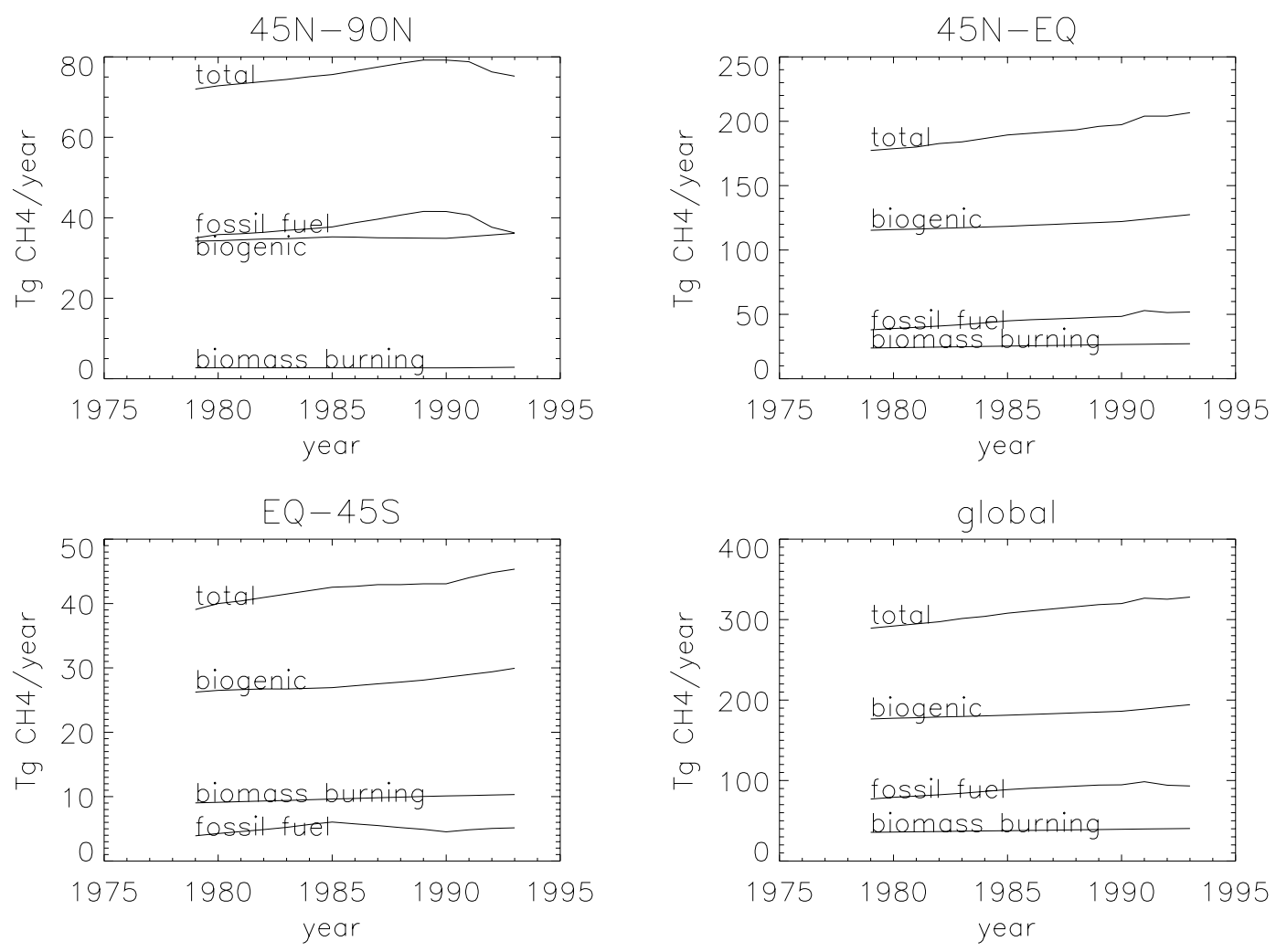

Fig. 1. Temporal development of anthropogenic $\mathrm{CH}_{4}$ emissions separated for biogenic, fossil fuel related, and biomass burning emissions. Global and 3 world regions.

ing et al., 1999; Hein et al., 1997). For a more comprehensive discussion on this topic we refer to the previous discussion in ACPD (Rayner, 2002; Kaminski, 2002).

As a starting point of the simulations we use the a priori natural and anthropogenic $\mathrm{CH}_{4}$ emissions that were obtained from Houweling et al. (1999), see Table 1. The anthropogenic part of these emissions, is with some small adaptations, consistent with the emissions from the EDGAR database (see below). Note that these a priori emissions do not contain inter-annual variability, and are not representative for a specific year. In a next step the measured concentrations are assimilated in the model using the measurements of the NOAA CMDL network in combination with model results (see Sect.3.2). In order to interpret the methane trends and to determine the inter-annual variability and trend of the methane emissions we calculate so called 'residual emissions'. These residual emissions are calculated from the difference of the top-down determined yearly methane emissions from a model simulation constrained by observed trends, and the bottom-up estimated time evolution of anthropogenic methane emissions from the EDGAR inventory. In this section we present the time evolution in the emission inventories and explain our method to calculate emissions from a model simulation and to derive the residual emissions.

\subsection{Time evolution of anthropogenic emissions}

In Fig. 1 we present the bottom-up estimated yearly anthropogenic methane emissions for the period 1979-1993 as adopted from Aardenne etal. (2001). For clarity we have aggregated the detailed $1 \times 1$ degree data set in four zonal regions $(45 \mathrm{~N}-90 \mathrm{~N} ; 0-45 \mathrm{~N} ; 0-45 \mathrm{~S} ; 45 \mathrm{~S}-90 \mathrm{~S})$ and three source categories (fossil fuel, biogenic and biomass burning). For comparison Houweling et al. (2000), used in his study emissions of 73.4, 234.5 and 63.4 , and $0.7 \mathrm{Tg} \mathrm{CH}_{4} \mathrm{yr}^{-1}$ for the anthropogenic emissions in the 4 regions, respectively. Natural emissions (including uptake by soils) were 27.4, 56.4, 74.5 and 1.2 $\mathrm{Tg} \mathrm{CH}_{4} \mathrm{yr}^{-1}$, respectively (see Table 1). Since there are no significant anthropogenic emissions south of $45 \mathrm{~S}$ this region is not included separately in Fig. 1. The fossil fuel emissions encompass all emissions associated with the production and consumption of fossil fuels. Biogenic emissions contain emissions from ruminants, ricepaddies and landfills. Biomass burning emissions include savannah fires, deforestation, waste burning and domestic biogenic fuel use. At middle and high northern latitudes fossil fuel and biogenic emissions are of equal importance. At low latitudes and in the Southern Hemisphere biogenic emissions are largest. Although especially biomass burning is known to exhibit a strong inter-annual variation, such vari- 
Table 2. NOAA stations used in this work to derive the model trends

\begin{tabular}{lrrr}
\hline Station & Code & Long & Lat \\
\hline Polar Front & CTM & $2 \mathrm{E}$ & $66 \mathrm{~N}$ \\
Cold Bay & CBA & $162 \mathrm{~W}$ & $55 \mathrm{~N}$ \\
Mould Bay & MBC & $119 \mathrm{~W}$ & $76 \mathrm{~N}$ \\
Barrow & BRW & $156 \mathrm{~W}$ & $71 \mathrm{~N}$ \\
Cape Meares & CMO & $123 \mathrm{~W}$ & $45 \mathrm{~N}$ \\
Key Biscayne & KEY & $80 \mathrm{~W}$ & $25 \mathrm{~N}$ \\
Mauna Loa & MLO & $155 \mathrm{~W}$ & $19 \mathrm{~N}$ \\
Cape Kumukahi & KUM & $154 \mathrm{~W}$ & $19 \mathrm{~N}$ \\
Guam & GMI & $144 \mathrm{E}$ & $13 \mathrm{~N}$ \\
Ascension Island & ASC & $14 \mathrm{~W}$ & $8 \mathrm{~S}$ \\
Tutuila,Samoa & SMO & $170 \mathrm{~W}$ & $14 \mathrm{~S}$ \\
South Pole & SPO & $24 \mathrm{~W}$ & $90 \mathrm{~S}$ \\
\hline
\end{tabular}

ations in anthropogenic emissions, other than by economical and demographic developments, are not taken into account in the bottom-up emission estimates. Calculated anthropogenic trends are markedly different in the mid-and-high-latitude Northern Hemisphere, and the rest of the world.

\subsection{Boundary conditions for top-down emission estima- tions}

For the top-down determination of the methane emissions we performed model simulations covering the period 1979 to 1993 . In these simulations the calculated methane mixing ratios are adjusted in the boundary layer, i.e. the first 3 model layers up to $600 \mathrm{~m}$ height, using a relaxation time scale of 10 days, to match the model zonal average to a prescribed set of zonally and monthly averaged methane mixing ratios derived from and consistent with observations. This timescale was choosen to include synoptic events, without constraining the model too strongly to the measurements. The choice to adjust these three model layers, rather than only the surface layer with a thickness of about $60 \mathrm{~m}$, is motivated by the fact that the observational (mostly marine) data-set is probably more representative for a mixed boundary layer than for continental surface layer concentrations. The observational data set consists of the independently determined zonally and monthly averaged methane mixing ratios for the year 1987 (which is in the middle of our modelling period) adopted from the inverse modelling study by Hein et al. (1997). The results of the zonal mean results of this independent inverse modeling study are useful as a constraint as the difference of the observed and calculated concentrations was minimized by their inversion. On top of this field we impose for the period 1984-1993 a trend derived from twelve background stations from the NOAA network for which there is a complete record during this time period (see Table 2).

The global annual trend was obtained by equally weight-

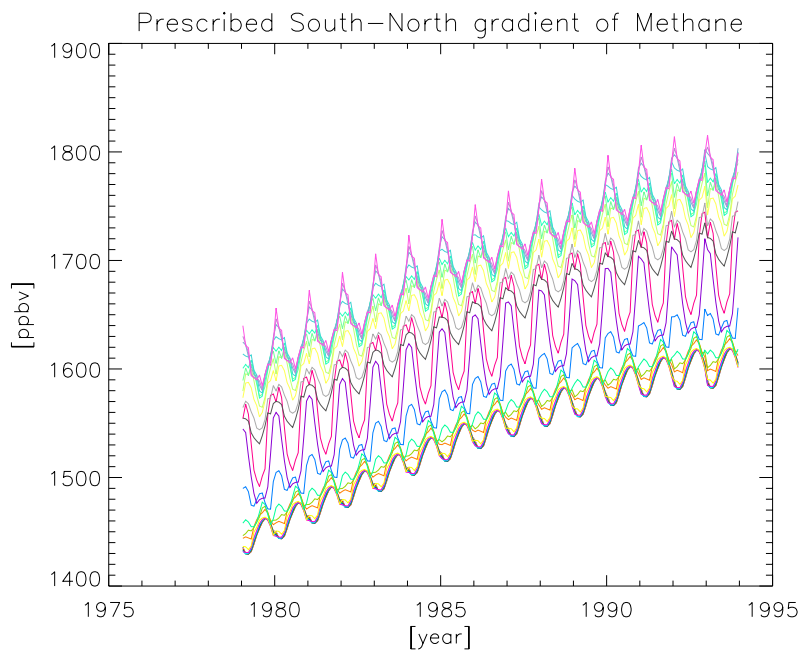

Fig. 2. Latitudinal and temporal evolution of prescribed methane volume mixing ratio [ppbv]. Each color represents a different latitude, starting from $86 \mathrm{~N}$ at the top in steps of 8 degrees.

ing of all stations. This yields a trend that is somewhat biased to the Northern Hemisphere (NH), which had most measurements. Alternatively, we could have given specific weigths to the stations depending on the distance of the 'footprints' associated with the measurements. Since we have only used remote stations we expect those footprints to be roughly comparable. Furthermore, it is questionable if the representativity of the few Southern Hemispheric stations is good enough to make our analysis more realistic and less subjective. Our approach is further supported by the fact that the magnitude of the methane north-south gradient has not changed during the period of our analysis (Dlugokencky et al., 1997). This supports that at least in the 1980s the trends in the $\mathrm{NH}$ and $\mathrm{SH}$ have been the same.

Prior to 1984 hardly any NOAA observations were available. Therefore, for the period 1979-1983 we use the observed trends evaluated by Etheridge et al. (1998).

By using the observed trends in combination with a zonal distribution, the main temporal and latitudinal features of the methane boundary conditions are well represented in the simulations, as shown in Fig. 2. The gradual increase of methane between 1979 and 1991 is included, as well as the smaller increases in 1992 and 1993 (see Introduction). In general the thus derived methane trends showed a good agreement with the individual station trends (see Sect. 5).

\subsection{Residual emissions}

The following method is used to calculate the residual emissions $\left(E^{\prime}\right)$. Consider the temporal evolution of methane mixing ratio $X$ at a specific longitude, latitude and height $\left(i, j, k_{1,3}\right)$ :

$\frac{d X_{i, j, k}}{d t}=F_{i, j, k}+G\left(X_{z o n, j, k}-X_{o b s, j}\right)$ 
where $F$ represents the concentration changes in the model due to emissions, transport and chemical loss at each gridpoint, and $G$ the nudging time constant $\left(0.1\right.$ day $\left.^{-1}\right)$. Integration of the second part on the right of Eq. (1) over one year and converting this term to mass units using a factor $M$ yields the yearly emissions or sinks $(d E)$ which need to be added to (or subtracted from) the model, in addition to the a priori natural and anthropogenic emissions, to force the model to its boundary conditions:

$d E=\int_{t}^{t+d t} G M_{j, k}\left(X_{z o n, j, k}-X_{o b s, j}\right) d t$

Note again that as an a priori estimate we used the emissions from Houweling et al. (1999), that did not contain interannual variations. To calculate the residual emissions variability $\left(d E^{\prime}\right)$ we remove the anthropogenic emission trend, by subtracting from $d E$ the difference between the bottomup determined anthropogenic emission $\left(E_{\text {Edgar }}\right)$ relative to its average over the 1979-1993 time period.

$d E^{\prime}=d E-E_{\text {Edgar }}+\overline{E_{\text {Edgar, 1979-1993 }}}$

The residual emission variability may still contain a trend, that was not taken into account in the original bottom-up estimate. Note that this residual trend is not necessarily only 'natural': it could also be a trend which was not represented in the EDGAR database (Aardenne et al., 2001).

A crucial assumption in our calculation of residual emissions is that the applied surface measurements and trends in the simulations are considered to be representative for larger atmospheric compartments, i.e. as zonal average and for the whole boundary layer. This is valid in first order because the monthly average measurements represent 'clean' background conditions. The representation problems connected with the use of surface network observations have been previously discussed by Houweling et al. (2000). To assess the accuracy of our method we present in the Appendix a sensitivity study in which we used a synthetic annually varying emission set to calculate the residual emissions.

In the following section we present the results integrated over four regions spanning from $90 \mathrm{~N}-45 \mathrm{~N}, 45 \mathrm{~N}$-Equator, Equator-45 S, and $45 \mathrm{~S}-90 \mathrm{~S}$. These large regions were chosen since we expect that the errors associated with our method start dominating the results when smaller regions are used to present the results.

\section{Results}

For the top-down determination of the methane emissions we performed three simulations covering the ERA15 period (1979-1993), and also some sensitivity studies. The three basic simulations differ such that we can assess the individual influences on:

- the interannual variability of methane emissions of the prescribed meteorology,
- the emission changes (of e.g. $\mathrm{NO}_{\mathrm{x}}$ and other precursor gases) and

- the stratospheric ozone column changes over this time period.

In the base simulation (S1) all three influences varied with time. This simulation has been used in previous analyses of the ozone budget as described by Lelieveld and Dentener (2000) and Peters et al. (2001). Both studies showed that ozone was realistically represented at various background locations, and a clear correlation of tropical ozone with the ENSO index was found, in good agreement with an earlier analysis of satellite observations (Ziemke et al., 1999). In a next step the monthly averaged $\mathrm{OH}$ fields associated with $\mathrm{S} 1$ were stored and used in further simulations. We verified that the use of the monthly averaged $\mathrm{OH}$ fields had marginal influence on our methane source calculations. In the second simulation (S2) meteorology was varied for the period 1979-1993 while the $\mathrm{OH}$ fields from S1 for the year 1987 were used. The third simulation (S3) uses one repeated meteorological year (1987), while OH for the period 1979-1993 derived from S1 was used.

Thus, all three simulations had the year 1987 in common, which can be used to detect possible discrepancies among the simulations. Further, the 3 simulations show the role of chemistry $(\mathrm{OH})$ versus transport. More simulations would be needed to determine the separate roles of sources, boundary conditions, and meteorological parameters such as water vapor and temperature. In all cases the model used the data-assimilation procedure for methane as explained in the previous section. All simulations used the a priori methane emissions derived from Houweling et al. (1999), and used a spin-up period of two years (1977-1978). It should be noted that the largest time-scale associated with the equilibration of $\mathrm{CH}_{4}$ corresponds to about 13 years (Wild and Prather, 2000), which is even larger than the tropospheric methane lifetime of about 9 years. However, using our assimilation method, such long simulations can be avoided, and the spinup time is sufficient to account for hemispheric mixing and tropospheric-stratospheric exchange. Further it should be mentioned that we used initial conditions for January 1977 that were already quite realistic.

We start our analysis by assessing by how much and by which mechanism in our simulations the methane destruction rates have varied. In Fig. 3 we show the tropospheric lifetime of methane calculated for the reference simulation (S1) as well as the two sensitivity simulations (S2, S3). The lifetimes are calculated as the quotient of the annual average tropospheric burden and the destruction rates of $\mathrm{CH}_{4}$ by $\mathrm{OH}$. In this analysis a fixed tropopause of $100 \mathrm{hPa}$ was used to define the tropospheric compartment. Calculated lifetimes are about 28 and 55 years in the $\mathrm{NH}$ and $\mathrm{SH}$ high latitude regions, respectively, and 6.5 years and 7.5 years for the $45 \mathrm{~N}-0$ and 0-45 S latitude regions. 

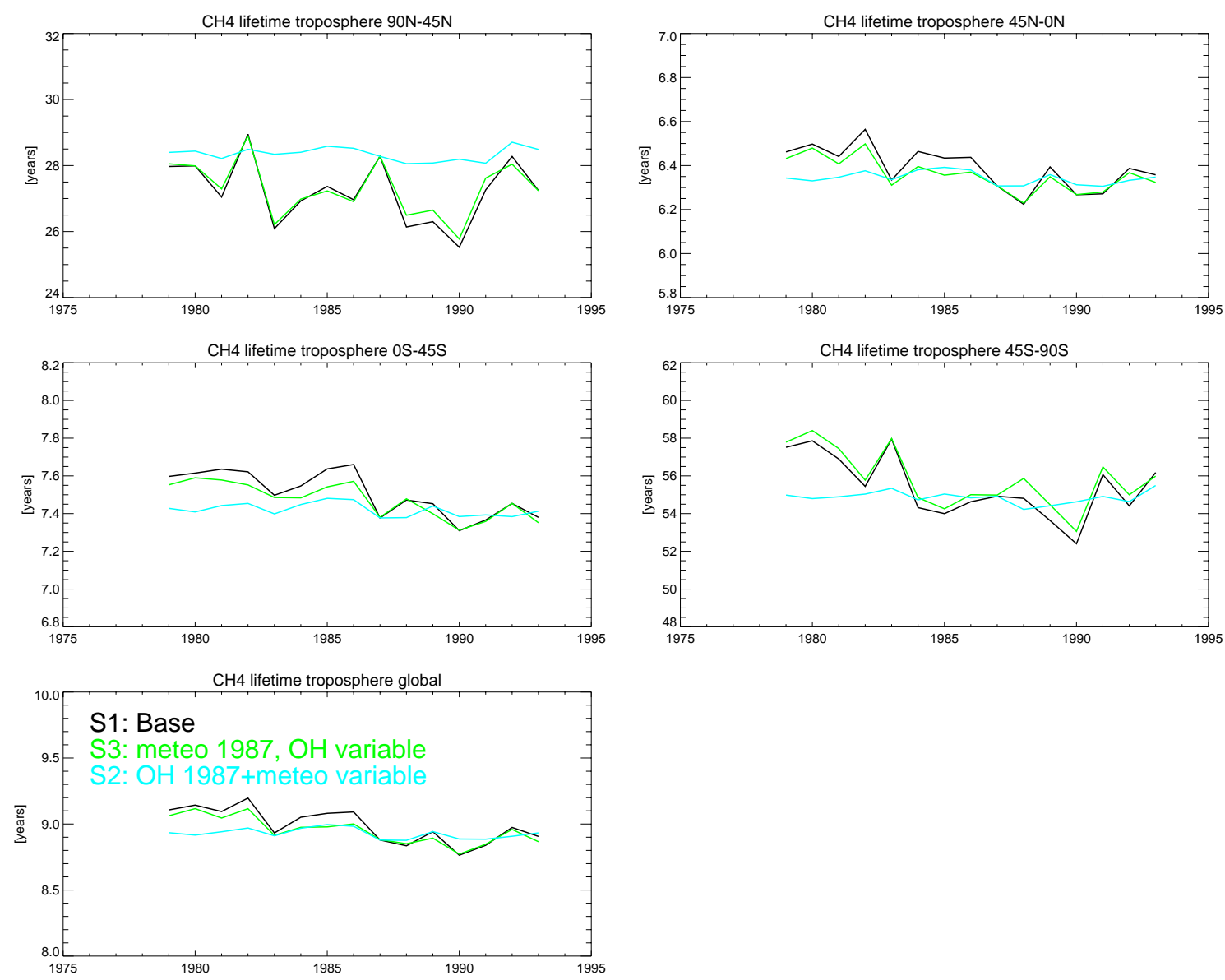

Fig. 3. Methane lifetime [years] determined for 3 simulations, for the 4 regions and global.

For the period 1979-1993, our simulations indicate a clear decrease of methane lifetimes in all four regions by $-0.23 \%$ to $-0.36 \%$ per year (Table 3 ). Globally, the calculated tropospheric methane lifetime decreases from 9.2 to 8.9 years $\left(-0.26 \pm 0.06 \% \mathrm{yr}^{-1}\right)$. Note that here and in the further text the uncertainty interval strictly refers to the \pm 1 standard deviation of the statistical analysis. The real uncertainty is probably larger, due to unaccounted model uncertainties. This lifetime can be compared with a range of $6.5-9.8 \mathrm{Tg}$ $\mathrm{CH}_{4} \mathrm{yr}^{-1}$ evaluated by Prather etal. (2001), although the comparison is rendered somewhat difficult due to differences in calculation methods (e.g. the tropopause height).

Considering a somewhat shorter period (1979-1991), thus largely excluding the effect of the eruption of Mt. Pinatubo, the calculated global $\mathrm{CH}_{4}$ trend is $-0.37 \pm 0.08 \% \mathrm{yr}^{-1}$. Over the full time period our calculated $\mathrm{OH}$ trend, weighted to $\mathrm{CH}_{4}$ destruction, is $+0.26 \% \pm 0.06 \mathrm{yr}^{-1}$, which is somewhat smaller than the $\mathrm{OH}$ trend of $0.46 \% \pm 0.6 \% \mathrm{yr}^{-1} \mathrm{de}-$ rived by Krol et al. (1998). The standard deviations in the calculated trends are large, indicating substantial inter-annual variability due to variability in meteorology (e.g. circulation patterns, convection) and variability in the chemical bound-
Table 3. Lifetime and trend of $\mathrm{CH}_{4}$ lifetime for $\mathrm{S} 1$ for the period 1979-1993. Lifetime is calculated for the year 1979 considering a tropopause height of $100 \mathrm{hPa}$ using annual average results. Uncertainties refer to the $\pm 1 \sigma$ standard deviation

\begin{tabular}{lrrr}
\hline Region & Trend [\% yr ${ }^{-1}$ ] & $\begin{array}{r}\text { Uncertainty of } \\
\text { trend }\left[\% \mathrm{yr}^{-1}\right]\end{array}$ & $\begin{array}{r}\text { Tropospheric } \\
\text { lifetime [year] }\end{array}$ \\
\hline 90N-45N & -0.23 & 0.20 & 28 \\
45N-EQ & -0.25 & 0.07 & 6.5 \\
EQ-45S & -0.27 & 0.07 & 7.5 \\
45S-90S & -0.36 & 0.15 & 55 \\
Global & -0.26 & 0.06 & 9.2 \\
\hline
\end{tabular}

ary conditions.

Our analysis shows that most of the decrease in $\mathrm{CH}_{4}$ lifetime in SH high latitude regions can be attributed to the influence of stratospheric ozone decline on photolysis rates and the associated enhanced $\mathrm{OH}$ production. Figure 3 clearly shows that the combined influence of emissions and strato- 

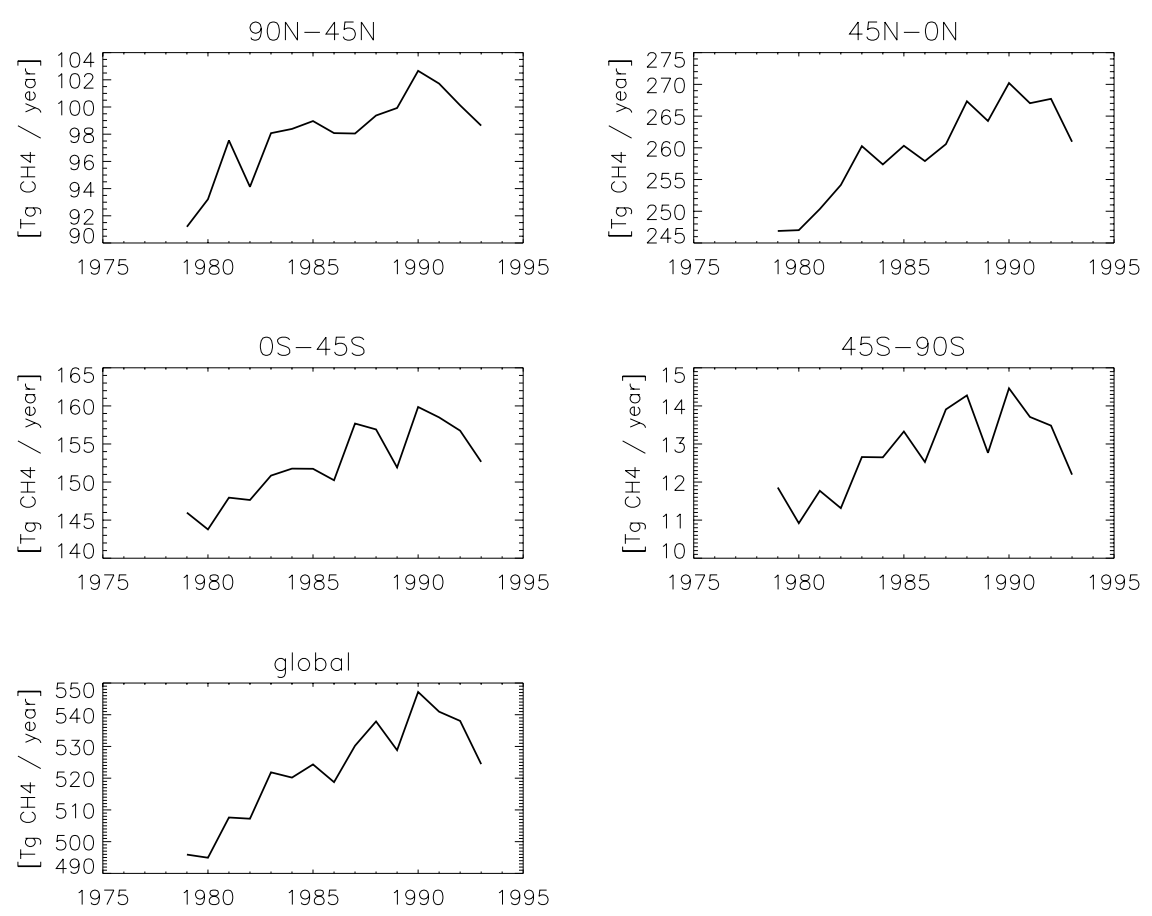

Fig. 4. Calculated emissions (Tg $\mathrm{CH}_{4} \mathrm{yr}^{-1}$ ) for the years 1979-1993.
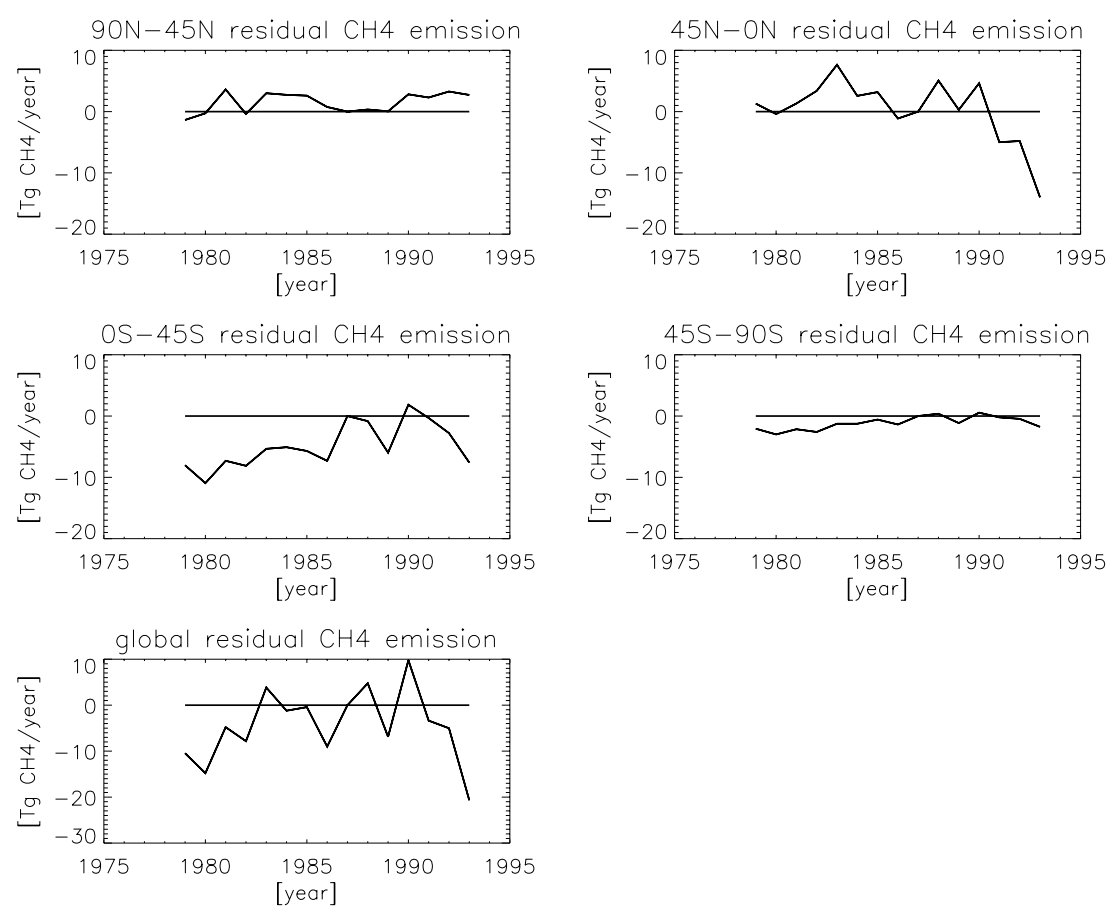

Fig. 5. Residual emissions (Tg $\mathrm{CH}_{4} \mathrm{yr}^{-1}$ ) for the base case and the 4 regions, calculated according to Eq. (3).

spheric ozone is determining most of the variability in the $\mathrm{CH}_{4}$ lifetime. Variability due to changing transport plays a smaller but not negligible role.

The change in $\mathrm{CH}_{4}$ lifetime in the tropical regions is consistent with the strong increase of $\mathrm{NO}_{\mathrm{x}}$ emissions in developing countries from 1979-1993. These increases amounted, e.g. in East Asia, China, and India to $70 \%, 75 \%$ and $55 \%$, respectively (Aardenne et al., 2001). Indeed a high sensitivity of the location of $\mathrm{NO}_{\mathrm{x}}$ emissions on $\mathrm{CH}_{4}$ lifetime was calculated by another model study (Gupta et al., 1998).

In Fig. 4 we present the calculated annual methane emissions for the four regions and the corresponding global total 
Table 4. Standard deviation of residual emissions (as a measure of variability), trend and uncertainty of this trend for the period 1979-1993. Units are $\left(\mathrm{Tg} \mathrm{CH}_{4} \mathrm{yr}^{-1}\right)$. Uncertainties refer to the $\pm 1 \sigma$ standard deviation interval. The trend is also calculated for the shorter period 1979-1991

\begin{tabular}{lrrrrr}
\hline Region & $\begin{array}{r}\text { Standard } \\
\text { deviation }\end{array}$ & $\begin{array}{r}\text { Trend } \\
1979-1993\end{array}$ & $\begin{array}{r}\text { Uncertainty } \\
\text { of trend }\end{array}$ & $\begin{array}{r}\text { Trend } \\
1979-1991\end{array}$ & $\begin{array}{r}\text { Uncertainty } \\
\text { of trend }\end{array}$ \\
\hline 90N-45N & 1.6 & 0.14 & 0.09 & 0.09 & 0.12 \\
45N-EQ & 5.2 & -0.64 & 0.27 & -0.17 & 0.24 \\
EQ-45S & 3.7 & 0.49 & 0.18 & 0.80 & 0.17 \\
45S-90S & 1.1 & 0.16 & 0.05 & 0.24 & 0.09 \\
Global & 7.8 & 0.16 & 0.48 & 0.98 & 0.43 \\
\hline
\end{tabular}

for the base run (S1). The calculated methane emissions (excluding the soil-sink) increased from 500 to $550 \mathrm{Tg} \mathrm{CH}_{4} \mathrm{yr}^{-1}$ during the period 1979-1991, but dropped by about $13 \mathrm{Tg}$ $\mathrm{CH}_{4} \mathrm{yr}^{-1}$ to $530 \mathrm{Tg} \mathrm{yr}^{-1}$ between 1991 and 1993. The calculated emissions are remarkably close to the a priori emissions of $523 \mathrm{Tg} \mathrm{yr}^{-1}$ for 1987 by Houweling et al. (2000). As expected the largest methane emissions are found in the low latitude zonal regions. However, since the area represented by the $45 \mathrm{~N}$-Equator region is twice as large as that from the $90 \mathrm{~N}-45 \mathrm{~N}$ region, the area weighted emissions in the two regions are rather similar.

In Fig. 5 we present the residual emissions, i.e. the emission changes corrected for the anthropogenic trend using the Edgar database (Eq. 3). Note that for clarity the 1987 residual emissions are taken to be 0 . Table 4 gives the standard deviations and trend-estimates corresponding to Fig. 5, and considering the full period 1979-1993 and also the shorter period 1979-1991.

From Fig. 5, and in comparison with Fig. 4, it is clear that most of the year-to-year changes in $\mathrm{CH}_{4}$ emissions are due to increasing anthropogenic emissions, which are adequately accounted for in the EDGAR emission database. The negative residual trend in the $0-45 \mathrm{~N}$ zonal region is strongly determined by the decrease in emissions in the year 1992 and 1993. The decrease is about $13 \mathrm{Tg} \mathrm{CH}_{4} \mathrm{yr}^{-1}$ and is likely associated with the Mt. Pinatubo volcanic eruption. For the shorter analysis period there is no significant residual trend. In the $\mathrm{SH}$ the model calculates a statistical significant residual trend of about $0.65 \pm 0.23 \mathrm{Tg} \mathrm{CH}_{4} \mathrm{yr}^{-1}$. However, this estimate is very uncertain because there are only three measurement sites in the $\mathrm{SH}$, of which the measurements cover the entire period.

Globally the emissions are consistent with the EDGAR database. The inter-annual variability of the global emissions amounts to about $8 \mathrm{Tg} \mathrm{CH}_{4} \mathrm{yr}^{-1}$. However, in the discussion section we will show that the real variability is probably higher.

Figure 6 presents, similar to Fig. 5, the global residual emissions calculated for the base simulation $\mathrm{S} 1$ and the two sensitivity studies S2 and S3. The common simulation year

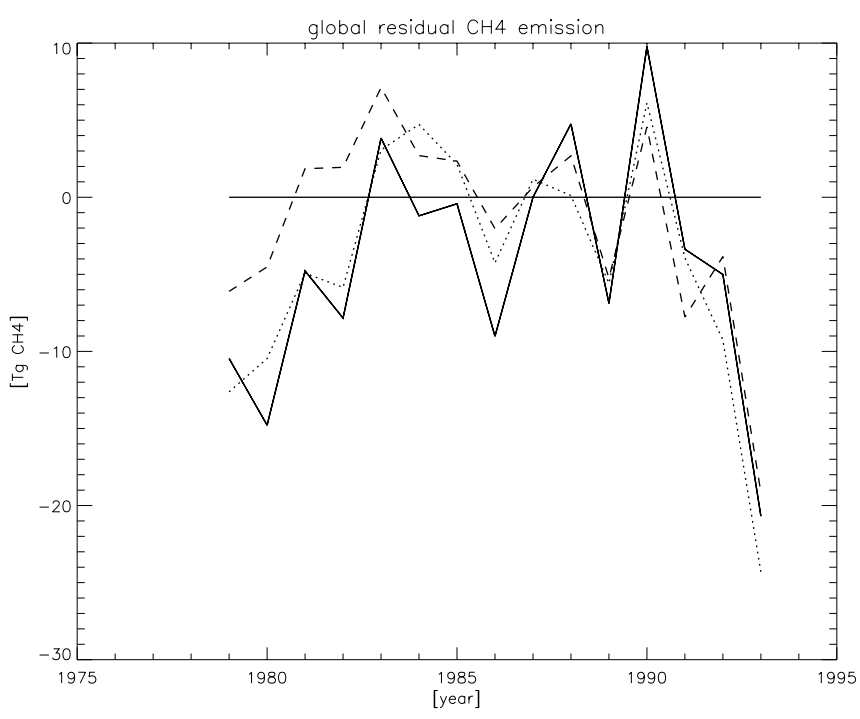

Fig. 6. Global residual emissions $\left(\mathrm{Tg} \mathrm{CH}_{4} \mathrm{yr}^{-1}\right)$ for the 3 case studies. Full line: S1 base simulation. Dashed line: S2 varying meteorology, constant $\mathrm{OH}$. Dotted line: S3 varying $\mathrm{OH}$, constant meteorology.

is 1987 and indeed similar residual emissions are calculated for this year.

The three simulations show rather similar calculated residual emissions. This shows that the applied measurements have the largest impact on the calculated residual emissions, and not the assumptions in the model simulations such as on $\mathrm{CH}_{4}$ emissions, $\mathrm{OH}$ distribution and transport. For example, the use of $1987 \mathrm{OH}$ fields (S3) does not change very much the calculated residual emissions for 1992 and 1993. This strengthens our conclusion that, integrated over the globe, the eruption of Mt. Pinatubo has lead to about $13 \mathrm{Tg} \mathrm{CH}_{4} \mathrm{yr}^{-1}$ lower emissions in the years 1992 and 1993.

Simulation S2 with $1987 \mathrm{OH}$ and varying meteorology shows a significant difference with base simulation S1 during the first years, indicating the influence of $\mathrm{OH}$, the differences become small after 1987. 

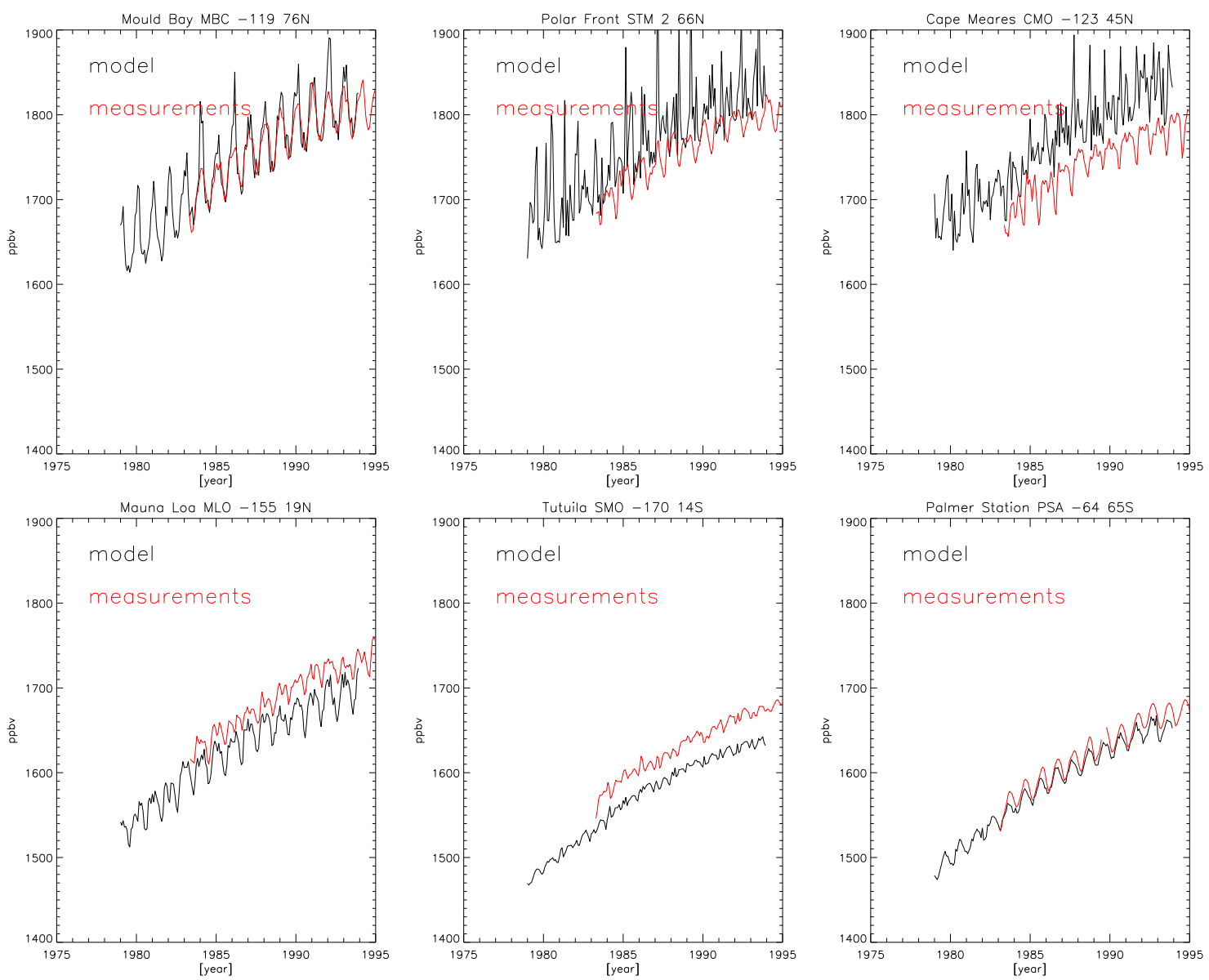

Fig. 7. A comparison of measured and observed $\mathrm{CH}_{4}$ concentrations at six NOAA stations.

Comparison of simulation S3 with fixed meteorology and variable $\mathrm{OH}$ from $\mathrm{S} 1$, with the base run $\mathrm{S} 1$ shows to what extent the year-to-year meteorological transport variability (transport, water vapor, temperature) influences the derived $\mathrm{CH}_{4}$ emissions. The transport variability mainly involves differences in methane concentrations due to differences in large-scale transport and convection. Inter-annual variability in methane destruction is mainly caused by changes in the transport efficiency of photo-oxidant precursor gases and by inter-annual variations of water vapor and temperature. These effects are taken into account in S1 and further analysed by Dentener et al. (2002).

We note here that we have performed a simple analysis of the correlation of the residual emissions in the four regions considered in this study and the annual average temperature variations in 12 world regions (e.g. Africa, OECD Europe, etc.). Only for a few regions (Africa and East Asia) statistically significant but weak correlations were found, which could indicate a methane emission-temperature sensitivity of the order $10 \mathrm{Tg} \mathrm{yr}^{-1} \mathrm{~K}^{-1}$. Likely candidates causing the variability are wetland emissions and biomass burning. However, as mentioned in the ACPD paper and in the reviewers and authors comments, there are several issues regarding the ability of our method to retrieve flux variability on regional scales, as well as the statistical evidence for the results, which render these findings rather speculative. For further information we refer the interested readers to these comments (Kaminski, 2002; Rayner, 2002) and to Sect. 5.

\section{Discussion}

The top-down calculated emissions, their trends and variability, are all subject to a number of uncertainties.

A first insight in the model performance may be derived from a comparison of computed concentrations and measurements at individual stations, that generally shows an agreement within \pm 50 ppbv (Fig. 7). We note here again, that our method does not require exact match of concentrations on all stations.

Trends, hemispheric and global averages of the concentrations are rather well reproduced by the model, but in general the model concentrations at those remote locations that are located in the same latitude band where also strong continental emissions occur tend to be somewhat underestimated (e.g. 
Samoa), whereas in the sources regions sometimes the model somewhat overestimates the $\mathrm{CH}_{4}$ concentrations and variability. This can be understood from our assimilation procedure which forces the model zonal mean towards the zonal mean of the model study by Hein et al. (1997), which has a different vertical resolution and mixing characteristics. It is not possible to quantify from the difference of the model and measurements an error in the calculated emissions. However we qualitatively judge that, especially on the global scale, the retrieved residual emission variability can not be simply attributed to a mismatch of model results and measurements.

Important uncertainties result from the $\mathrm{OH}$ fields that are used. Our emission estimates are obtained using $\mathrm{OH}$ fields, which are calculated on-line within the model. Thus, these $\mathrm{OH}$ fields are not, as is commonly done, calibrated to give an optimized sink for methyl chloroform. Nevertheless, the calculated global emissions of 500-550 $\mathrm{Tg} \mathrm{CH}_{4} \mathrm{yr}^{-1}$ are consistent with the range of net emissions (including a soil sink) derived by Houweling et al. (2000), i.e. $479-528 \mathrm{Tg} \mathrm{CH}_{4} \mathrm{yr}^{-1}$ based on a methylchloroform (MCF) calibrated $\mathrm{OH}$ field. However, the calibration of $\mathrm{OH}$ with MCF is also associated with uncertainties. For example, the uncertainty listed by Sander et al. (2000) for the reaction between MCF and $\mathrm{OH}$ is $10 \%$, although the uncertainty of this reaction relative to the reaction between $\mathrm{OH}$ and $\mathrm{CH}_{4}$ may be less. Further, the uncertainty of the absolute calibration of MCF is about 5\% (Prinn et al., 1995). It is also generally assumed that emissions of MCF are accurate within about $2 \%$ (e.g. Midgley and McCulloch, 1995). There is however no independent test to verify this rather low uncertainty. The stratospheric and oceanic loss rates of MCF are not well determined, which may lead to systematic errors of 1-2\% (Hein et al., 1997). Houweling et al. (2000) suggest that the methylchloroform lifetimes determined by chemical-transport models strongly depend on the model inter-hemispheric exchange times, which can be erroneous by $10 \%$. Therefore we argue that an uncertainty of at least $10 \%$ is associated with these top-down determined global source strengths of methane. In view of the uncertainties involved with the 'calibration' of $\mathrm{OH}$ using MCF, which are at least $10 \%$, an adjustment of $\mathrm{OH}$ does not add much value to our study. Moreover, we realize that the fact that we are calculating MCF-consistent $\mathrm{OH}$ fields, without adjustment, might be rather fortuitous. To our experience, changes in emissions, rate constants or removal processes, within their limit of uncertainty, may easily cause differences in global $\mathrm{OH}$ of the order $10 \%$ or larger.

Further, it is still questionable whether or not an $\mathrm{OH}$ trend is present in the considered time period. Recently, there has been a lengthy discussion between Krol et al. (2001) and Prinn and Huang (2001), also see the introduction. A recent paper by Prinn et al. (2001) reports a strong positive trend of $15 \% \pm 22 \%$ for the period $1979-1989$ (or $1.3 \% \mathrm{yr}^{-1}$ ) followed by a strong decrease the following decade. At this point there is little to add to their points of view. Our 'best' model simulation (S1) suggests that an increasing $\mathrm{OH}$ and decreasing turn-over time of methane during the period 1979-1993 as shown in Fig. 3, which is consistent with the results of Krol et al. (2001) and Karlsdòttir et al. (2000). A more comprehensive study on the trend and variability of $\mathrm{OH}$ will be presented elsewhere (Dentener et al., 2002).

Another model uncertainty arises from the simplified way to treat the stratospheric methane sink. In this model version an annual amount varying between 38 and $42 \mathrm{Tg} \mathrm{CH}_{4} \mathrm{yr}^{-1}$ was destroyed in the upper 5 model levels in the stratosphere, which results were derived from a 2-D model calculation by Brühl and Crutzen (1993). In addition, stratospheric chlorine increased during the period 1979-1993, possibly influencing the stratospheric lifetime of methane. In this study the impact of this uncertainty is expected to be small, since chlorine accounts for only about $20 \%$ of the stratospheric $\mathrm{CH}_{4}$ oxidation. It is worth to mention here that the stratospheric methane budgets did not show unexpected variations or drifts.

Without doubt the largest uncertainty pertaining to our method is whether a prescribed zonal average $\mathrm{CH}_{4}$ concentration field derived from an independent inverse modeling study and valid for a single year modified with a trend derived from a limited set of measurements can be used to retrieve trends in emissions and to deduce variability. To estimate the uncertainty we present in the Appendix a test with prescribed emissions, which indicates that the regional trends of emissions can be determined with accuracy better than $50 \%$, and much better on the global scale. This can be compared with the results of more conventional inversion methods (e.g. Green's function approach). In principle these methods can provide optimized emission estimates including a model consistent error estimate. However, at the same time we should be modest on the usefulness of the present generation of inversion techniques. For example, Houweling et al. (1999) use an inversion of the methane cycle to calculate a global emission of $528 \pm 90 \mathrm{Tg} \mathrm{yr}^{-1} \mathrm{CH}_{4}$ (or 17\%). On the hemispheric scales the relative uncertainties are even higher (SH: 50\%, NH: 20\%). Different models and inversion techniques give rather different results, e.g. Hein et al. (1997) reports a global emission uncertainty in the order of $8 \%$. Most likely these uncertainties are larger since they do not account for uncertainties that are hard-wired into the method. It should also be noted that their results strictly pertain the average emissions of one specific period.

Related to the use of our technique is the question whether the calculated global and annual emission variability of $8 \mathrm{Tg}$ $\mathrm{CH}_{4} \mathrm{yr}^{-1}$ is realistic and what the meaning of the variability on the sub-hemispheric scales is. First of all it is interesting to note that the inverse model study by Hein et al. (1997) gives estimates for the avarage emissions of two different periods (1983-1989, and 1991-1993) which differ only by $10 \mathrm{Tg} \mathrm{yr}^{-1} \mathrm{CH}_{4}$ or $2 \%$. In that study the chemical and transport characteristics for the different target periods were identical, and the study used 18 stations. Their findings are thus fairly consistent with our results, although the analysis time 
scales are somewhat different.

As we showed in the Appendix, our method tends to reduce the real variability by $20-30 \%$. Furthermore the aggregrated emissions are more accurate than those on the finer scales. Especially in regions with a lack of measurements the errors can be large. The most likely candidates causing emission variability are (tropical) wetlands and biomass burning emissions. In our model wetland emissions amount to $145 \mathrm{Tg}$ $\mathrm{CH}_{4} \mathrm{yr}^{-1}$ (see Table 1), with a large fraction occuring in the tropics. Thus, relatively small variations of these emissions may explain the calculated global variation. Model calculations by Walter et al. (2001) suggest a $\pm 1 \sigma$ variability of $15 \mathrm{Tg} \mathrm{CH}_{4} \mathrm{yr}^{-1}$. The main factors influencing variability are the temperature and the hydrological cycle (e.g. the water table/precipitation), with sometimes opposite effects.

Another methane source that is known to exhibit a strong inter-annual variability is biomass burning, especially savannah burning. Emission estimates for biomass burning emissions (i.e. savannah burning, waste burning, and deforestation) range from about $40 \mathrm{Tg} \mathrm{yr}^{-1} \mathrm{CH}_{4}$ (Houweling et al., 1999) to less than $13 \mathrm{Tg} \mathrm{CH}_{4} \mathrm{yr}^{-1}$ (Olivier and Berdowski, 2001). Langenfelds et al. (2001) suggest that biomass burning emissions are larger by $15 \%$ to $90 \%$ in 'high-burning' years in excess of mean levels of other years. This suggest that even the lower end of the range $\left(2-6 \mathrm{Tg} \mathrm{CH}_{4} \mathrm{yr}^{-1}\right)$ could explain substantial part of our calculated variability. The upper range of $11-34 \mathrm{Tg} \mathrm{CH}_{4} \mathrm{yr}^{-1}$ would be inconsistent with our results, assuming that biomass burning and wetland emissions can be considered independent. We note that an independent satellite based study by Barbosa et al. (1999) indicated a variability of biomass burning of the order of $25 \%$ for the African continent. It is not clear if this number can be extrapolated to the globe.

Like for wetland emissions we would expect for biomass burning emissions that the variability would correlate with meteorological parameters such as temperatures or precipitation. In addition we mention that it is possible that wetland emissions and biomass burning emissions are to some extent anti-correlated, by opposing effects of the large-scale hydrological cycle.

Biomass burning may also affect $\mathrm{NO}_{\mathrm{x}}$ and $\mathrm{CO}$ emissions. Except for a small trend related to population increase, our model simulations did not include this. These emissions may in turn influence regional ozone and $\mathrm{OH}$ abundance. To give some indication on the sensitivity of our model to biomass burning $\mathrm{NO}_{\mathrm{x}}$ emisions we make a comparison with the trend resulting from anthropogenic $\mathrm{NO}_{\mathrm{x}}$ emissons. In the tropical regions from 1979-1993 these emissions may have increased by about $4.8 \mathrm{Tg} \mathrm{N}$ leading to a corresponding integrated increase of $\mathrm{OH}$ (weighted to $\mathrm{CH}_{4}$ ) destruction rates) over this period by about $4 \%$. In comparison, Gupta et al. (1998) found a similar sensitivity of about $3 \%$ for an additional $5 \mathrm{Tg} \mathrm{NO}_{\mathrm{x}}$ emitted in the tropics. The continent with the largest biomass burning emissions is Africa. $\mathrm{NO}_{\mathrm{x}}$ emissions from savannah burning in Africa are about $2 \mathrm{Tg}$ (Marland et al., 2000). Barbosa et al. (1999) used 6 years of AVHRR data to estimate the burned area in Africa. Their lower estimate of $\mathrm{NO}_{\mathrm{x}}$ emissions is $2.8 \pm 0.75 \mathrm{Tg} \mathrm{Nyr}^{-1}$. Thus, assuming an inter-annual variability of these emissions for whole Africa of $25 \%$, the corresponding influence on integrated tropical $\mathrm{OH}$ would be about $0.4 \% \mathrm{yr}^{-1}$ (corresponding to an emission of ca. $2 \mathrm{Tg} \mathrm{CH}_{4} \mathrm{yr}^{-1}$ ). This is probably an upper estimate for the $\mathrm{NO}_{\mathrm{x}}-\mathrm{OH}-\mathrm{CH}_{4}$ sensitivity, since these emissions occur predominantly during a limited time in the dry season and under very stable conditions. Therefore this relatively low influence of $\mathrm{NO}_{\mathrm{x}}$ emission variability on methane concentrations would not alter our conclusions. However if the $\mathrm{NO}_{\mathrm{x}}$ emissions would be significantly higher, or the chemistry would be significantly different from that in other regions, this could alter our conclusions. Several research efforts by our as well as other groups are now underway to quantify inter-annual variability of biomass burning emissions and the resulting effect on photo-chemistry.

\section{Conclusions}

We used a set of multi-annual global 3-D chemical transport model (CTM) simulations to check the consistency of changes in photochemistry (including the nonlinearity of $\mathrm{OH}$ chemistry), meteorology, methane sources, and observations. Our semi inverse analysis provides a first estimate of $\mathrm{CH}_{4}$ emission trend and variability on a 15 years timescale. The reference simulation yields a rather consistent picture of global methane emissions, atmospheric chemistry and observations. In this simulation we used annually varying meteorological fields derived from the ECMWF re-analysis for the years 1979-1993, annually varying $\mathrm{NO}_{\mathrm{x}}, \mathrm{CO}$, and NMHC emissions (Aardenne et al., 2001) and ozone column boundary conditions obtained from TOMS. The methane concentrations were adjusted in the boundary layer to a monthly and zonally averaged concentration field based on observations, with the observed global annual trend superimposed to this field. The amount of methane destroyed by photochemical reactions in the model and replenished into the lower model layers is therefore a good measure of the methane emissions needed to balance the observations.

Globally, during the period 1979-1993 the calculated tropospheric methane lifetime decreases from 9.2 to 8.9 years $\left(-0.26 \pm 0.06 \% \mathrm{yr}^{-1}\right)$. This is consistent with the work of Krol et al. (1998).

The calculated methane emissions trends are consistent with the time evolution of methane emissions from an independent database compiled by Aardenne et al. (2001). For the period 1979-1993 this trend amounts to $2.7 \mathrm{Tg} \mathrm{CH}_{4} \mathrm{yr}^{-1}$. The eruption of Mt. Pinatubo in 1991 may have lead to a strong decrease of methane emissions by about $13 \mathrm{Tg}$ $\mathrm{CH}_{4} \mathrm{yr}^{-1}$.

The calculated interannual variability of (natural) methane sources is of the order of $8 \mathrm{Tg} \mathrm{CH}_{4} \mathrm{yr}^{-1}$. We showed in 

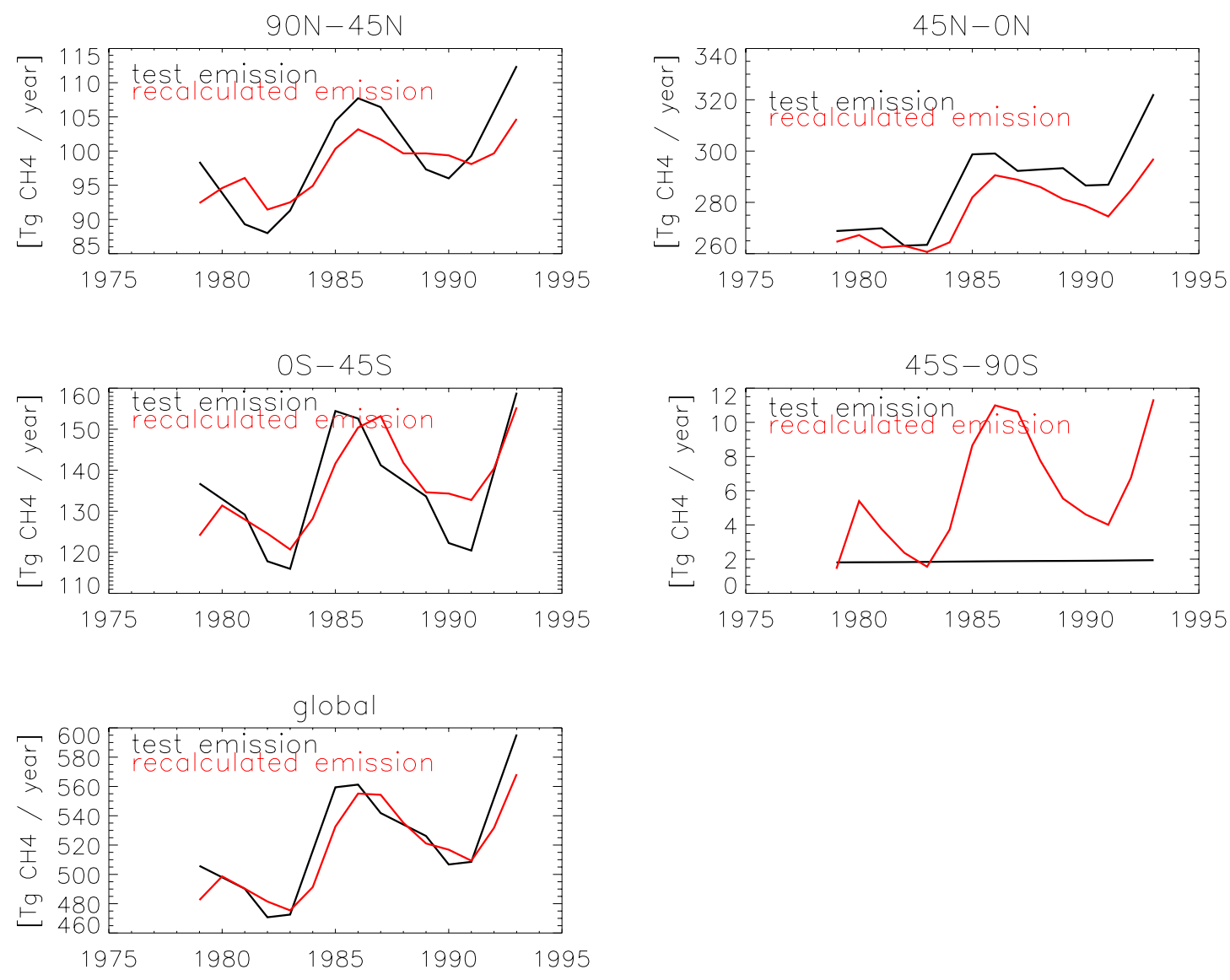

Fig. 8. Synthetic emission data set, and re-calculated emissions using a limited amount of station data.

the Appendix that our method using a limited set of observations tends to give an underestimate of this variability by $15 \%$ globally and $40 \%$ in the NH. Sensitivity studies showed that in studies of methane trends it is most important to include the trends of the oxidant fields, and to a lesser extent the transport variability.

The variability of the oxidant fields, however, does not strongly influence the variability of the retrieved emissions (see Fig. 6), as can be expected. Most variability in the retrieved emissions is probably caused by changes in biomassburning and/or wetland emissions, both of which depend on meteorological factors such as temperature or rainfall. An analysis of correlation between regional scale emissions and large scale temperatures, indeed suggests for some regions such a relationship. However, the statistical evidence as well as the applicability of our method to sub-hemispheric scales prohibits to draw firm conclusions. It is also worthwhile to mention that we did not find significant correlations between a five-month running average of the residual natural emissions and the El Niño Southern Oscillation index.

The main uncertainty in this work is associated with the use of a limited set of measurements to derive global emissions and trends. The uncertainties associated with our method were evaluated using an synthetic emission dataset, which was used to 'generate' concentrations at the locations of the measurement stations. Using these synthetic emissions we were able to calculate trends and variability with an accuracy of about $50 \%$. The real-world accuracy is probably better, since the imposed variabilities were unrealisticly high. Thus the order of magnitude of the error introduced by our method is of similar magnitude as the a-posteriori uncertainty estimated using more formal inversion techniques.

We believe that the results presented in this study, which were obtained with a relatively simple method, give valuable insights into model uncertainties and indicate what can be learned from future multi-annual inversions of the methane cycle, especially on emission trend issues. Satellite observations which are now becoming available together with inversions/data assimilation will further help to reduce the uncertainties of $\mathrm{CH}_{4}$ emissions.

\section{Appendix: Test with synthetic emissions}

Our method can be seen as a rather informal inverse technique, similar to the more rigorous and formally more correct method described in e.g. Law and Simmonds (1996). 
Table 5. Statistical analysis of the synthetic (S) annual emissions, and the retrieved (R) annual emissions $\left(\mathrm{Tg} \mathrm{CH}_{4} \mathrm{yr}^{-1}\right)$. The standard deviation (sd) is a measure of the inter-annual variability. The trend is associated with a calculated uncertainty (trend unc.) using the $\pm 1 \sigma$ interval. Correlation coefficient $r^{2}$ is calculated using annual values of $\mathrm{S}$ and $\mathrm{R}$

\begin{tabular}{|c|c|c|c|c|c|c|c|c|c|}
\hline Region & $\mathrm{r}^{2}$ & mean & mean & trend & trend & $\begin{array}{r}\text { trend } \\
\text { unc. } \\
\mathrm{S}\end{array}$ & $\begin{array}{r}\text { trend } \\
\text { unc. } \\
\mathrm{R}\end{array}$ & sd & $\mathrm{sd}$ \\
\hline $90 \mathrm{~N}-45 \mathrm{~N}$ & 0.72 & 99.3 & 97.9 & 1.00 & 0.68 & 0.34 & 0.17 & 7.1 & 4.1 \\
\hline $45 \mathrm{~N}-\mathrm{EQ}$ & 0.87 & 286.1 & 276.4 & 3.10 & 2.02 & 0.59 & 0.48 & 16.9 & 11.9 \\
\hline EQ-45S & 0.62 & 135.2 & 136.1 & 0.76 & 1.48 & 0.78 & 0.52 & 13.1 & 10.8 \\
\hline $45 S-90 S$ & 0.34 & 1.9 & 5.9 & 0.00 & 0.39 & 0.00 & 0.18 & 0.04 & 3.33 \\
\hline Global & 0.84 & 522.6 & 516.3 & 4.88 & 4.58 & 1.70 & 1.32 & 35.0 & 29.6 \\
\hline
\end{tabular}

The largest uncertainty pertaining to our method is whether a prescribed zonal field for a single year modified with a trend derived from a limited set of measurements can be used to retrieve trends in emissions and to deduce variability. To evaluate this difficult problem, we generated a set of synthetic emissions, which consisted of the emission data-set evaluated by Houweling et al. (2000) supplemented with an artificial, but realistic trend of $1 \% \mathrm{yr}^{-1}$ for all anthropogenic emissions. In addition we applied an artificial variability on the biomass burning and wetland emissions, which are considered to be the main sources of inter-annual variability. We assumed a period of 2 and 4 years and amplitude of $33 \%$ and $25 \%$, respectively. The variability of the synthetic emissions was on purpose chosen very high to provide a rigorous test for our method. In the next step the monthly and zonal average field for 1987 was calculated, and the surface layer $\mathrm{CH}_{4}$ concentrations at the locations of the 12 NOAA sites were used to calculate the global 1979-1993 trend. These zonal average concentrations and their trends were then used to 'nudge' the model. The further steps followed the same procedure as described before, using varying $\mathrm{OH}$ fields and varying meteorology. Shortly, the method tests to what extent the information contained in a limited amount of data can be used to retrieve relatively variable and complex emissions. However, the method is not able to test errors in model transport and station representativity on the model's spatial scale. Figure 8 shows the annual average original synthetic and recalculated emissions. The corresponding statistical parameters are presented in Table 5. Overall, the average emissions, the variability and trend are indeed recovered using the method, and high correlation is found between the prescribed and re-calculated emissions. Except for the southernmost region, the retrieved emissions are within a few percent of the original emissions. Retrieved trends are about $30 \%$ lower on the Northern Hemisphere and about $100 \%$ higher on the Southern Hemisphere. Globally the errors seem to balance. Except in the $45 \mathrm{~S}-90 \mathrm{~S}$ compartment, the retrieved variability is $20-30 \%$ less than the prescribed ones, due to the use of the 'background' station data, and the associated loss of information.

The largest obvious deviation is found in the region $45 \mathrm{~S}-$ $90 \mathrm{~S}$, where spurious emissions are calculated. However, the maximum deviation of the retrieved and synthetic emissions is of similar magnitude (about $10 \mathrm{Tg} \mathrm{CH}_{4} \mathrm{yr}^{-1}$ ) as in other regions. Interestingly, the emissions calculated using 'real' measurements show much less variability than in this synthetic case. We therefore think that the annual trends and 2-D $\mathrm{CH}_{4}$ fields are more representative for the 'real' situation. Given the rigorous conditions in this test it is therefore quite likely that the trend of $\mathrm{CH}_{4}$ can be retrieved with an accuracy substantially better than $50 \%$.

\section{References}

Aardenne, J. A., Dentener, F. J., Olivier, J. G. J., Klein Goldewijk, C. G. M., and Lelieveld, J.: A $1^{\circ} \times 1^{\circ}$ resolution data set of historical anthropogenic trace gas emissions for the period 1890-1990, Global Biogeochem. Cycles, 15, 909-928, 2001.

Barbosa, P.M., Stroppiana, D., Gregoire, J.-M., and Pereira, J. M. C.: An assessment of vegetation fire in Africa (1981-1991): Burned areas, burned biomass, and atmospheric emission, Global Biogeochem. Cycles, 18, 933-95, 1999.

Bekki, S., Law, K. S., and Pyle, J. A.: Effect of ozone depletion on atmospheric $\mathrm{CH}_{4}$ and $\mathrm{CO}$ concentrations, Nature, 371, 595-597, 1994.

Brühl, C. and Crutzen, P. J.: MPIC two-dimensional model, NASA Ref. Publ., 1292, 103-104, 1993.

Dentener, F. J. and Crutzen, P. J.: A three-dimensional model of the global ammonia cycle, J. Atmos. Chem., 19, 331-369, 1994.

Dentener, F. J., Peters, W., Krol, M., van Weele, M., Bergamaschi, P., and Lelieveld, J.: On the inter-annual-variability and trend of $\mathrm{OH}$ and the lifetime of $\mathrm{CH}_{4}$ : 1979-1993 global CTM simulations, J. Geophys. Res., submitted, 2002.

Dlugokencky, E. J., Masarie, K. A., Tans, P.P., Conway, T. J., and Xiong, X.: Is the amplitude of the methane seasonal cycle changing?, Atmos. Environ., 31, 21-26, 1997.

Dlugokencky, E. J., Masarie, K.A., Lang, P. M., and Tans, P.P.: Continuing decline in the growth rate of the atmospheric methane burden, Nature, 393, 447-450, 1998. 
Etheridge, D. M., Steele, L. P., Francy, R. J., and Langenfelds, R. L.: Atmospheric methane between 1000 A. D. and present: Evidence of anthropogenic emissions and climatic variability, J. Geophys. Res., 103, 15 979-15 993, 1998.

Fortuin, J.P.F. and Kelder, H.: An ozone climatology based on ozonesonde and satellite measurements, J. Geophys. Res., 103, 31 709-31 734, 1998.

Fung, I., John, J., Lerner, J., Matthews, E., Prather, M., Steele, L. P., and Fraser, P. J.: Three-dimensional model synthesis of the global methane cycle, J. Geophys. Res., 96, 13 033-13 065, 1991.

Ganzeveld, L., Lelieveld, J., and Roelofs, G. J.: A dry deposition parameterization for sulfur oxides in a chemistry and general circulation model, J. Geophys. Res., 103, 5679-5694, 1998.

Gibson, R., Kallberg, P., and Uppsala, S.: The ECMWF re-analysis (ERA) project, ECMWF Newsletter 73, European Centre for Medium Range Weather Forecasts, Reading, England, 1997.

Guelle, W., Balkanski, Y. J., Schulz, M., Dulac, F., and Monfray, P.: Wet deposition in a global size-dependent aerosol transport model, Comparison of a 1 year $\mathrm{Pb}^{210}$ simulation with ground measurements, J. Geophys. Res., 103, 11 429-11 445, 1998.

Gupta, M., Cicerone, R. J., and Elliot, S.: Perturbation to global tropospheric oxidizing capacity due to latitudinal redistribution of surface sources of $\mathrm{NO}_{x}, \mathrm{CH}_{4}$, and $\mathrm{CO}$, Geophys. Res. Lett., 21, 3931-3934, 1998.

Heimann, M.: The global atmospheric tracer model TM2, Tech. Rep. 10, Deutsches Klimarechenzentrum, Hamburg, Germany, 1995.

Hein, R., Crutzen, P. J., and Heimann, M.: An inverse modeling approach to investigate the global atmospheric methane cycle, Global Biogeochem. Cycles, 11, 43-76, 1997.

Hogan, K. B. and Harris, R. C.: Comment on "A decrease in the growth rate of atmospheric methane in the Northern Hemisphere during 1992" by E. J. Dlugokencky et al., Geophys. Res. Lett., 21, 2445-2446, 1994.

Houweling, S., Dentener, F. J., and Lelieveld, J.: The impact of nonmethane hydrocarbon compounds on tropospheric photochemistry, J. Geophys. Res., 103, 10 673-10 696, 1998.

Houweling, S., Kaminski, T., Dentener, F. J., Lelieveld, J., and Heimann, M.: Inverse modeling of methane sources and sinks using the adjoint of a global transport model, J. Geophys. Res., 104, 26 137-26 160, 1999.

Houweling, S., Dentener, F. J., Lelieveld, J., Walter, B., and Dlugokencky, E. J.: The modeling of tropospheric methane: How well can point measurements be reproduced by a global model?, J. Geophys. Res., 105, 8981-9002, 2000.

Kaminski, T.: Interactive comment on Trends and inter-variability of methane emissions derived from 1979-1993 global CTM simulations by F. Dentener et al., Atmos. Chem. Phys. Discuss., 2, S76-S79, 2002.

Karlsdòttir, S., Isaksen, I. S. A., G., G. M., and Berntsen, T.: Trend analysis of $\mathrm{O}_{3}$ and $\mathrm{CO}$ in the period 1980-1996: A threedimensional model study., J. Geophys. Res., 105, 28 907-28 933, 2000.

Krol, M. and Van Weele, M.: Implications of variation of photodissociation rates for global atmospheric chemistry, Atmos. Env., 31, 1257-1273, 1997.

Krol, M., van Leeuwen, P. J., and Lelieveld, J.: Global OH trend inferred from methylchloroform measurements, J. Geophys. Res.,
103, 10 697-10711, 1998.

Krol, M., Van Leeuwen, P. J., and Lelieveld, J.: Reply to the comment of Prinn and Huang on "Global $\mathrm{OH}$ trend inferred from methylchloroform measurements' by Krol et al., J. Geophys. Res., 106, 23 159-23 164, 2001.

Landgraf, I. and Crutzen, P. J.: An efficient method for online calculations of photolysis and heating rates, J. Atmos. Sci., 55, 863878, 1998.

Langenfelds, R., Francey, J., Pak, B., Steele, P., Lloyd, J., Trudinger, C., and Allison, C.: The use of multi-species for interpreting interannual variability in the carbon cycle, 2001.

Lassey, K. R., Lowe, D. C., Brenninkmeijer, C. A. M., and Gomez, A. J.: Atmospheric methane and its carbon isotopes in the Southern Hemisphere: Their time series and an instructive model, Chemosphere, 26, 95-109, 1993.

Law, R. and Simmonds, I.: The sensitivity of deduced $\mathrm{CO}_{2}$ sources and sinks to variations in transport and imposed surface concentrations, Tellus, Ser. B, 48, 613-625, 1996.

Lelieveld, J. and Dentener, F. J.: What controls tropospheric ozone?, J. Geophys. Res., 105, 3531-3551, 2000.

Lelieveld, J., Crutzen, P. J., and Dentener, F. J.: Changing concentration, lifetime and climate forcing of atmospheric methane, Tellus, Ser. B, 50, 128-150, 1998.

Louis, J. F.: A parametric model of vertical eddy fluxes in the atmosphere, Boundary Layer Meteorol., 17, 187-202, 1979.

Marland, G., Boden, T.A., and Andres, R.J.: $\mathrm{CO}_{2}$ emissions. trends: A compendium of data on global change, Tech. rep., Carbon Dioxide Analysis Center, Oak Ridge National Laboratory, Oak Ridge, Tenn USA, 2000.

McPeters, R.: Nimbus-7 total ozone mapping spectrometer (toms) data products user's guide, Reference publication 1384, NASA, Washington DC, 1996.

Midgley, P. M. and McCulloch, A.: The production and global distribution of emissions to the atmosphere of 1,1,1-trichloroethane (methyl chloroform), Atmos. Environ., 29, 1601-1608, 1995.

Olivier, J.G. J. and Berdowski, J.: Global emissions sources and sinks, in: The climate system, (Eds) Guicherit, R. and Heij, B. J., A.A. Balkema Publishers/Swets and Zeitlinger Publishers, Lisse, The Netherlands, 2001.

Olivier, J.G.J., Bouwman, A.F., Berdowski, J.J. M., Veldt, C., Bloos, J. P. J., Visschedijk, A. J. H., van der Maas, C. W. M., and Zandveld, P. Y. J.: Sectoral emission inventories of greenhouse gases for 1990 on a per country basis as well as on $1^{\circ} \times 1^{\circ}$, Environ. Sci. Policy, 2, 241-263, 1999.

Peters, W., Krol, M., Dentener, F. J., and Lelieveld, J.: Identification of an El Niño oscillation signal in a multiyear global simulation of tropospheric ozone, J. Geophys. Res., 106, 19389$19402,2001$.

Prather, M., Ehhalt, D., Dentener, F., Derwent, R., Dlugokencky, E., Holland, E., Isaksen, I., Katima, J., Kirchhoff, V., Matson, P., Midgley, P., and Wang, M.: Atmospheric chemistry and greenhouse gases, chapter 4, in: Climate Change 2001, The scientific basis: Contribution of working group I to the Third assessment report of the Intergovernmental Panel on Climate, (Eds) Houghton, J. T., Ding, Y., Griggs, D. J., Noguer, M., van der Linden, P. J., Dai, X., Maskell, K., and Johnson, C. A., p. 881, Cambridge University Press, Cambridge, United Kingdom and New York, NY, US., 2001.

Prinn, R. G. and Huang, J.: Comment on "Global OH trend inferred 
from methylchloroform measurements" by Krol et al., J. Geophys. Res., 106, 23 151-23 157, 2001.

Prinn, R. G., Weiss, R.F., Miller, B.R., Huang, J., Alyea, F. N., Cunnold, D. M., Fraser, P.B., Hartley, D.E., and Simmonds, P. G.: Atmospheric trends and lifetime of $\mathrm{CH}_{3} \mathrm{CCl}_{3}$ and global average hydroxyl radical concentrations based on 1978-1994 ALE/GAGE measurements, Science, 269, 187-192, 1995.

Prinn, R.G., Huang, J., Weiss, R.F., Cunnold, D. M., Fraser, P. J., Simmonds, P. G., Mcculloch, A., Harth, C., Salameh, P., O’Doherty, S., Wang, R. J., Porter, L., and Miller, B. R.: Evidence for substantial variations of atmospheric hydroxyl radicals in the past two decades, Science, 292, 1882-1888, 2001.

Rayner, P.: Interactive comment on Trends and inter-variability of methane emissions derived from 1979-1993 global CTM simulations by F. Dentener et al., Atmos. Chem. Phys. Discuss., 2, S158-S163, 2002.

Russell, G. and Lerner, J.: A new finite-differencing scheme for the tracer transport equation, J. Appl. Meteorol., 20, 1483-1498, 1981.
Sander, S.P., Friedl, R. R., DeMore, W. B., Kurylo, M. J., Hampson, R.F., Huie, R.E., Moortgat, G. K., Ravishankara, A. R., Hampson, C.E. K., J., C., and Molina, M. J.: Chemical kinetics and photochemical data for use in stratospheric modelling, NASA/JPL publ. 00-003 Eval. 13, Jet Propul. Lab., Pasadena, California, USA, 2000.

Tiedke, M.: A comprehensive mass flux scheme for cumulus parameterization in large-scale models, Mon. Weather Rev., 117, 1779-1800, 1989.

Walter, B.P., Heimann, M., and Matthews, E.: Modeling modern methane emissions from natural wetlands 2., interannual variations 1982-1993, J. Geophys. Res., D24, 34 207-34 129, 2001.

Wild, O. and Prather, M.: Excitation of the primary tropospheric chemical mode in a global three-dimensional model, J. Geophys. Res., 105, 24 647-24 660, 2000.

Ziemke, J., Chandra, S., and Bartia, P.: Seasonal and interannual variabilities in tropical tropospheric ozone, J. Geophys. Res., 104, 21 245-21 442, 1999. 